\title{
Identification of differentially methylated regions (DMRs) of neuronatin in mice
}

\author{
Yuxin $\mathrm{Xu}^{\dagger}$, Zhiquan Liu ${ }^{\dagger}$, Tiedong Wang ${ }^{\dagger}$, Xianju Chen, Jichao Deng, Mao Chen and Zhanjun Li
}

\begin{abstract}
Background: Neuronatin (NNAT) is a paternal-inherited imprinted gene, first discovered in the rat neonatal brain, where it plays vital roles for neuronal growth, brain development, and metabolic regulation. The maternal imprint of NNAT has been identified in mice; however, the differentially methylated regions (DMRs) involved in the monoallelic expression of NNAT have not yet been investigated.
\end{abstract}

Results: In this study, we confirmed expression of two isoforms of the NNAT ( $\alpha$ and $\beta$ ) in the mice brain via quantitative RT-PCR. Additionally, the methylation profile of the CpG island located in the NNAT gene locus was determined in the mice liver, brain, sperm, and the MIl oocyte via bisulfite sequencing PCR.

Conclusion: In summary, we provide the first evidence for tissue- and gamete-specific methylation patterns of CpG3 that are located on exon 1, to be putative DMR of NNAT in mice.

Keywords: NNAT, DMR, Mice, Isoform

\section{Background}

Genomic imprinting leads to unequal expression of paternal and maternal alleles in offspring, which is essential for normal embryogenesis, fetal growth, and functional postnatal behavior (Surani 1998; Li et al. 1999; Das et al. 2013). The differentially methylated regions (DMRs) are established during gametogenesis and regulate the parent-specific expression of imprinted genes. DMRs with allele specific methylation have also been used in cancer diagnosis (Ushijima 2005; Bonin et al. 2016). Although 125 imprinted genes have been identified in mice to date (according to the Gene imprint database; http://www. geneimprint.com/), very little has been published about the DMRs of those imprinted genes (Gu et al. 2014).

$N N A T$ is a highly conserved imprinted gene among humans, mice, cattle, and pigs, containing two alternatively spliced transcripts ( $\alpha$ and $\beta$ ) (Cheng et al. 2007;

\footnotetext{
${ }^{*}$ Correspondence: lizj_1998@jlu.edu.cn

${ }^{\dagger}$ Yuxin Xu, Zhiquan Liu and Tiedong Wang contributed equally to this work

College of Animal Science, Jilin University, 5333\#, Xi'an Road, Changchun 130062, China
}

Schulz et al. 2009). Previous studies have revealed the parental-specific expression of NNAT to be associated with the methylation status of the CpG island located in the NNAT promoter sequence of pigs (Chen et al. 2014; Gu et al. 2014) and rabbits (Duan et al. 2015). A second intronic DNA sequence within the mouse NNAT with a length of $250 \mathrm{bp}$ was defined as putative DMR and was revealed to act as a transcriptional activator in Drosophila (Sowpati et al. 2008). In addition, the hyper methylation of human NNAT frequently occurs in pediatric acute leukemia and Wilms Tumors (Kuerbitz et al. 2002; Hubertus et al. 2013).

All of these previously published findings suggest that there is no definite DMR of NNAT in mice. With this background, we sought to identify the DMRs of mice NNAT via quantitative real-time PCR (q-PCR) and bisulfite sequencing PCR (BSP) analyses.

\section{Results and discussion}

In this study, we proposed a model of two NNAT isoforms $(\alpha$ and $\beta)$ using GenBank and Ensembl databases. Furthermore, putative DMRs of NNAT (CpG 1 and 
CpG 2, CpG 3, CpG I2) were identified via comparative sequencing analysis and methyprimer (Fig. 1a). The results of q-PCR and RT-PCR demonstrated high expression of both of the transcripts ( $\alpha$ and $\beta$ ) in the brain of mice, but not in their liver, which is consistent with the UniGene database (Fig. 1b, c). Previous studies have found two transcripts of NNAT that are widely expressed in most of tissues, including in livers and kidneys of cattle (both fetal and adult) and in 2-month-old pigs (Zaitoun and Khatib 2006; Cheng et al. 2007), suggesting different NNAT expression profiles between species.

To identify the DMR of mice NNAT, methylation profiles of CpG 1, CpG 2, CpG 3, and CpG I2 were determined in both the brain and the liver using BSP. The results revealed hypermethylation of CpG1 (Fig. 2a vs. e), CpG2 (Fig. 2b vs. f), and CpG I2 (Fig. 2d vs. h) in both brain and liver. However, we found tissue-specific methylation patterns of CpG3 in the brain (29.33\%) and liver (66\%) (Fig. 2c vs. g). These results point towards the methylation status of $\mathrm{CpG} 3$ accounting for the expression difference of NNAT in liver vs. brain. In addition, tissuespecific methylation patterns revealed CpG3 (located on exon 1) to be a putative DMR of the NNAT in mice (Fig. 2c).

Generally, DNA methylation patterns of imprinted genes were established in both sperm and oocyte, which were reprogrammed subsequent after fertilization (Seisenberger et al. 2013). To identify the gamete-specific methylation pattern of CpG3 in mice NNAT, the DNA methylation profile of $\mathrm{CpG} 3$ in sperm and oocyte was determined via BSP. The results reveal hypomethylation in sperm (10\%) and hypermethylation in MII oocytes (90\%) (Fig. 3). In summary, the gamete-specific methylation patterns suggest that the imprinting marks of NNAT are established by a sex-specific mechanism, confirming CpG3 as the DMR of NNAT.

\section{Conclusions}

Here, we studied the expression patterns of two isoforms of mice NNAT ( $\alpha$ and $\beta$ ), and identified the CpG3 of mice NNAT (located on exon 1) as putative DMR.The data revealed hypermethylation of exon 1 to be associated with the silencing of mice NNAT, suggesting the NNAT gene transcriptional status to be correlated with the methylation status of exon 1, while being independent of both intron and $5^{\prime}$ UTR.

\section{Methods}

Tissue samples

The brain and liver were collected from two-month old ICR mice and immediately stored in liquid nitrogen until further use. Spermatozoa and MII oocytes were harvested using previously published protocols (Chen et al. 2014).

\section{RT-PCR and quantitative real-time PCR (q-PCR)}

Total RNA from liver and brain $(n=5)$ was isolated with TRNzol-A+ reagent (TIANGEN, Beijing, China) according to manufacturer's instructions. The cDNA was synthesized with DNAse I (Fermentas, Shanghai, China) treated total RNA via the BioRTcDNA First Stand Synthesis Kit (Bioer Technology, Hangzhou, China).

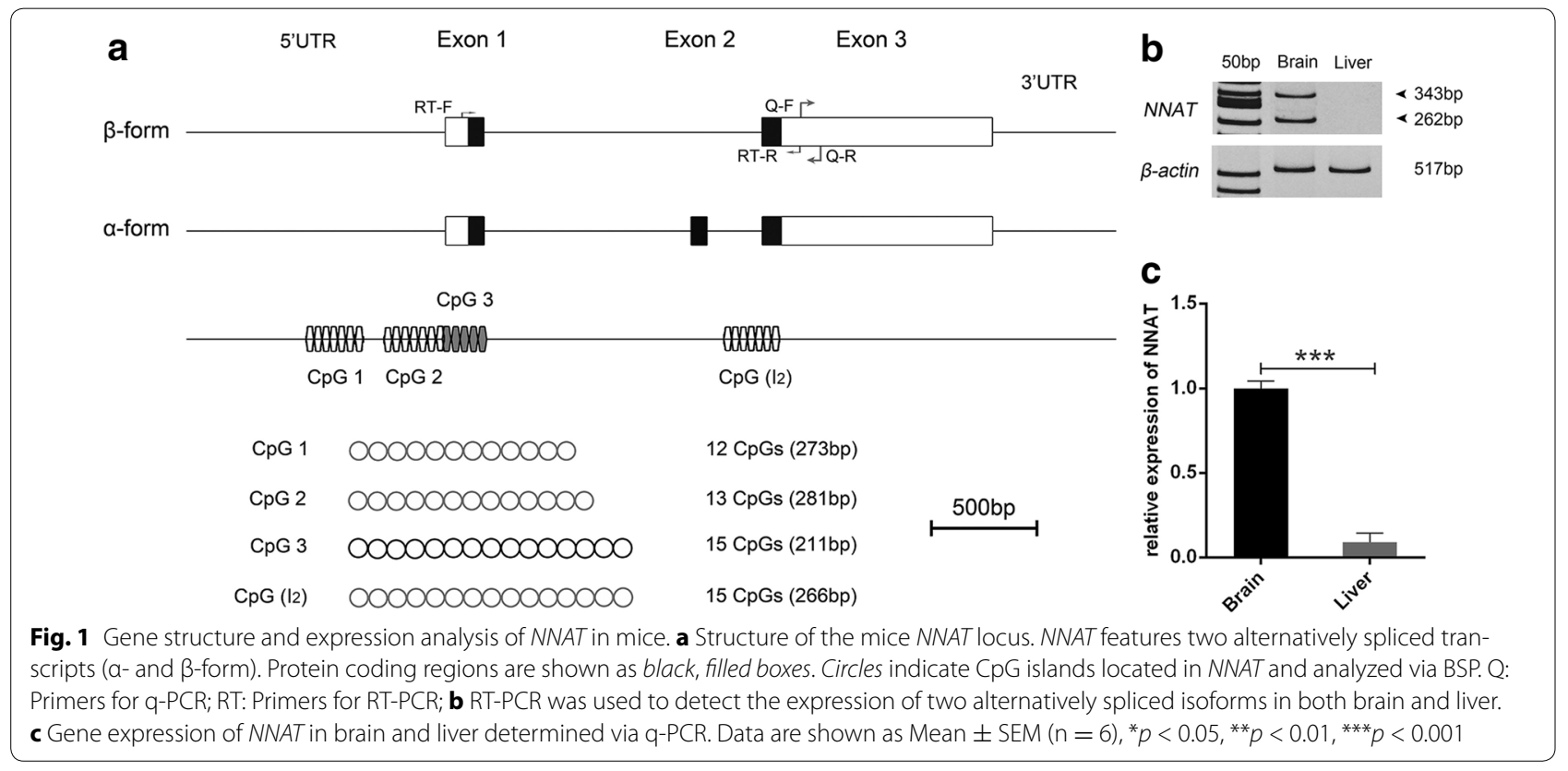




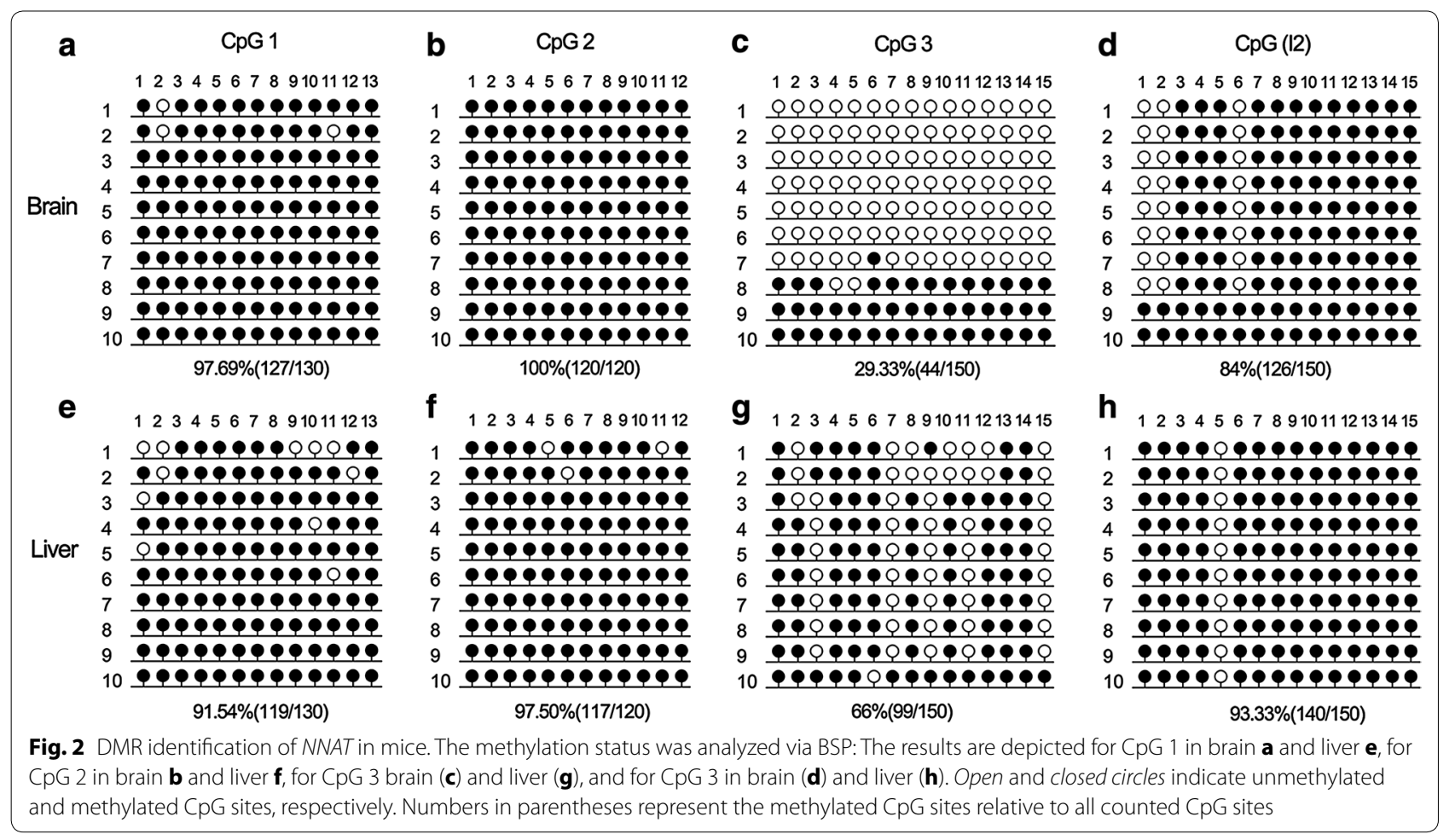

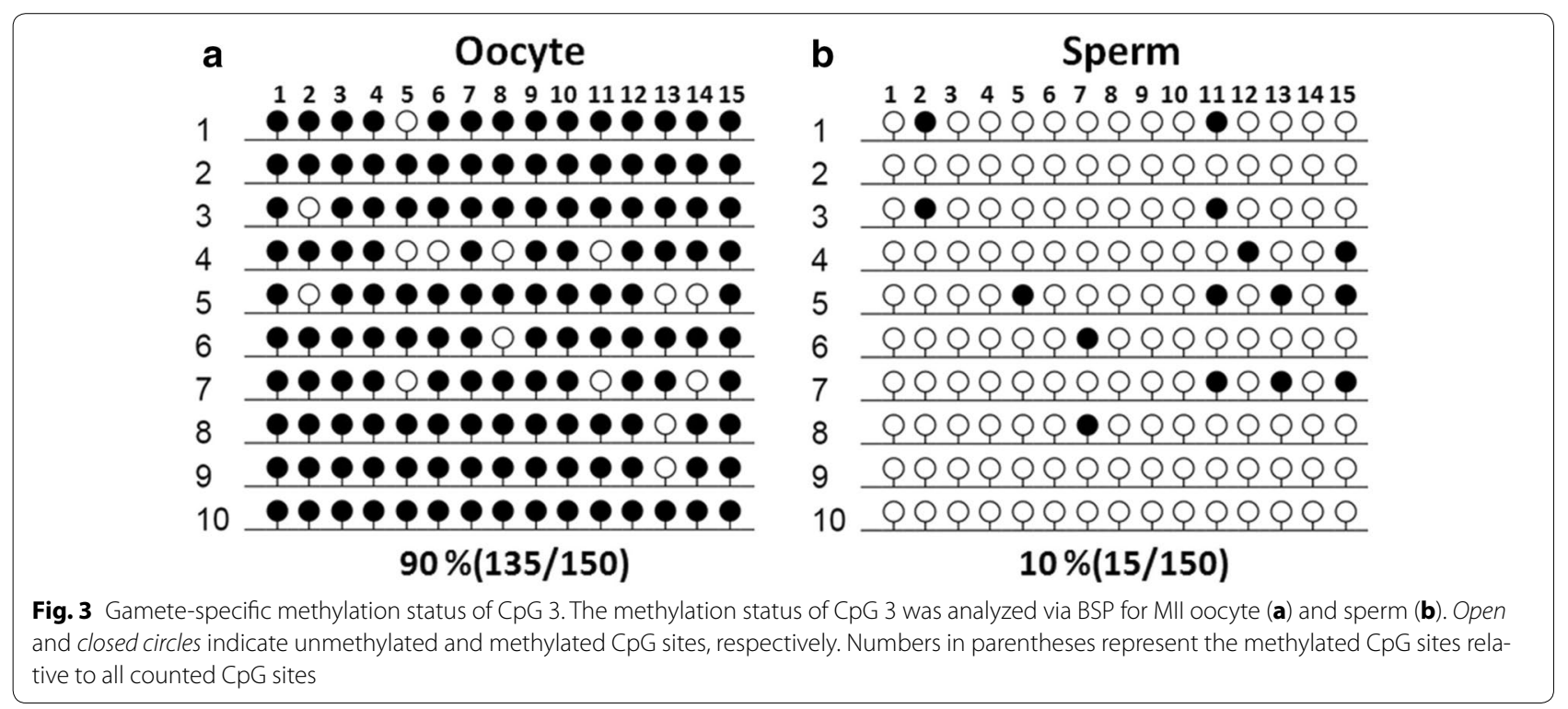

The BioEasy SYBR Green I Real Time PCR Kit (Bioer Technology, Hangzhou, China) was used to perform q-PCR, using the BIO-RAD Iq5 Multicolor Real-Time PCR Detection System. The reaction conditions were as follows: $95{ }^{\circ} \mathrm{C}$ for $3 \mathrm{~min}$, followed by 40 cycles of $95{ }^{\circ} \mathrm{C}$ for $10 \mathrm{~s}$ for DNA denaturation, $60{ }^{\circ} \mathrm{C}$ for $15 \mathrm{~s}$ for primer annealing, and $72{ }^{\circ} \mathrm{C}$ for $30 \mathrm{~s}$ for extension. Relative gene expression normalized to $\beta$-actin was determined via the $2^{-\Delta \Delta C T}$ formula. All experiments on gene expression were performed in triplicate. The gene expression data was presented as mean \pm SEM. Primers used for q-PCR and RT-PCR are listed in Table 1.

Bisulfite sequencing PCR

Bisulfite sequencing PCR (BSP) was performed to determine methylation of NNAT CpG islands. The CpGenome 
Table 1 Primers for q-PCR and RT-PCR

\begin{tabular}{llll}
\hline Gene & Primer sequence $\left(\mathbf{5}^{\prime} \boldsymbol{\rightarrow} \mathbf{3}^{\prime}\right)$ & $\left.\mathbf{T}_{\mathbf{a n n}} \mathbf{(}^{\circ} \mathbf{C}\right)$ & Length $(\mathbf{b p})$ \\
\hline NNAT-RT & F:GCTCATCATCGGCTGGTACA & 60 & 343 \\
& R:CTTGGCAAGTGCTCCTCTGA & & 262 \\
B-actin-RT & F:ATATCGCTGCGCTGGTCGTC & 60 & 517 \\
& R:AGGATGGCGTGAGGGAGAGC & & \\
NNAT-q & F:GTCCCCTGTGTTCCCTCGTC & 60 & 81 \\
& R:TGTCGGTGCTGCTTTTCTGG & \\
Actin-q & F:GGCACCACACYTTCTACAATG & 60 & 133 \\
& R:GGGGTGTGAAGGTCTCAAAC & & \\
\hline
\end{tabular}

$T_{a n n}$ the annealing temperature, $R T$ the primers for RT-PCR, $Q$ the primers for $\mathrm{q}-\mathrm{PCR}$

TM Turbo Bisulfite Modification Kit (Millipore, Jaffrey, $\mathrm{NH}$, USA) was used for bisulfate treatment of genomic DNA of both liver and brain according to the manufacturer's instructions. Bisulfite-treatment of the DNA of sperms $\left(\mathrm{n}=1 \times 10^{3}\right)$ and matured oocytes $(\mathrm{n}=100)$ was done according to the instructions of the EZ DNA Methylation-Direct $^{\mathrm{TM}}$ Kit (Zymo Research,CA). Nested PCR was used to amplify CpG islands, followed by T-vector cloning (positive clones, $\mathrm{n}=10$ ) and subsequent sequencing analysis. The BSP primers are listed in Table 2.

Table 2 Primers for BSP

\begin{tabular}{|c|c|c|c|}
\hline Gene & Primer sequence $\left(5^{\prime} \rightarrow 3^{\prime}\right)$ & $\mathrm{T}_{\text {ann }}\left({ }^{\circ} \mathrm{C}\right)$ & Length (bp) \\
\hline \multirow[t]{4}{*}{ CpG1-BSP } & $\begin{array}{l}\text { O-F:TTTTGGTGTTTTAGTTGTATAG } \\
\text { CGAA }\end{array}$ & 55 & 504 \\
\hline & $\begin{array}{l}\text { O-R:AATACAAACCTCTTAATTCGA } \\
\text { CACA }\end{array}$ & & \\
\hline & I-F:TAGAGGTTCGTATTTGTTTCGTAG & 55 & 275 \\
\hline & $\begin{array}{l}\text { I-R:TTTTTCTACATTCCTACTAATC } \\
\text { CGT }\end{array}$ & & \\
\hline \multirow[t]{4}{*}{ CpG2-BSP } & $\begin{array}{l}\text { O-F:GAGCGGGAATTAATAGTTAG } \\
\text { AAAAG }\end{array}$ & 55 & 526 \\
\hline & $\begin{array}{l}\text { O-R:ACTAATCTCGAAATCCGCTAC } \\
\text { TAAA }\end{array}$ & & \\
\hline & I-F:GTATGTAGAATTTGTAGGTTTGGG & 54 & 282 \\
\hline & I-R:CTCTTACCACCTAAATACGCATAC & & \\
\hline \multirow[t]{4}{*}{ CpG3-BSP } & O-F:GGTAGAGTAGAATTTTTTGGA & 58 & 590 \\
\hline & O-R:CACCCCTAAATCTTTATTCCC & & \\
\hline & $\begin{array}{l}\text { I-F:TTTAGGTGGTAAGAGGGTATTT } \\
\text { AAGGTA }\end{array}$ & 60 & 211 \\
\hline & I-R:AATACATACTCACCTACAACA & & \\
\hline \multirow[t]{4}{*}{ 12-BSP } & $\begin{array}{l}\text { O-F:TTTGGAATGTTGTATTTATTGG } \\
\text { GTAGGA }\end{array}$ & 55 & 558 \\
\hline & $\begin{array}{l}\text { O-R:CCCCTCACTAACCTTAACAAAT } \\
\text { ACTCCTC }\end{array}$ & & \\
\hline & $\begin{array}{l}\text { I-F:TAGTTGTTTTTGATTGGTGGATA } \\
\text { AGT }\end{array}$ & 56 & 266 \\
\hline & I-R:AACTCGCTACCTACGCTCCC & & \\
\hline
\end{tabular}

$T_{a n n}$ the annealing temperature, $O$ outside primers of the BSP, I inside primers of the BSP

\section{Statistical analysis}

Data were analyzed using student's $t$-tests via SPSS 22.0 software (SPSS Inc., Chicago, IL, USA) and a $p<0.05$ was considered as statistically significant. DNAman and online software tools Methprimer (http://www.urogene. org/methprimer/) and Bio Analyzer (http://biq-analyzer. bioinf.mpi-inf.mpg.de/tools/MethlationDiagrams/index. php) were used for the methylation analysis.

\section{Abbreviations}

NNAT: neuronatin; PCR: polymerase chain reaction; qPCR: quantitative realtime PCR; BSP: bisulfite sequencing PCR; DMR: differentially methylated region; RT-PCR: reverse transcription PCR.

\section{Authors' contributions}

$Y X, T W$ and ZL conceived, designed and performed the experiments and wrote the manuscript. XC and JD collected the samples. MC performed the statistical analysis. ZL provided guidance. All authors read and approved the final manuscript.

\section{Acknowledgements}

We thank Peiran Hu, Xue Chen and Tingting Yu at the Embryo Engineering Center for their critical technical assistance.

\section{Competing interests}

The authors declare that they have no competing interests.

\section{Ethics approval and consent to participate}

All experiments about mice were carried out in accordance with the guidelines on animal care and supervised by the Animal Care Center and Use Committee of Jilin University. All experimental protocols were approved by the Ethics Committee of Jilin University.

\section{Funding}

This project was gratefully funded from the National Natural Science Foundation of China (Grant No. 31201080 and 31272394). Agricultural science and technology research of Guangdong province (2011A020102003).

Received: 18 April 2016 Accepted: 21 November 2016 Published online: 28 November 2016

\section{References}

Bonin CA, Lewallen EA, Baheti S, Bradley EW, Stuart MJ, Berry DJ et al (2016) Identification of differentially methylated regions in new genes associated with knee osteoarthritis. Gene 576(1 Pt 2):312-318

Chen X, Wang T, Lv Q, Wang A, Ouyang H, Li Z (2014) DNA methylationmediated silencing of neuronatin (NNAT) in pig parthenogenetic fetuses. Gene 552(1):204-208

Cheng H-C, Zhang F-W, Deng C-Y, Jiang C-D, Xiong Y-Z, Li F-E et al (2007) NNAT and DIRAS3 genes are paternally expressed in pigs. Genetics Selection Evolution 39(5):1-9

Das R, Lee YK, Strogantsev R, Jin S, Lim YC, Ng PY et al (2013) DNMT1 and AIM1 Imprinting in human placenta revealed through a genome-wide screen for allele-specific DNA methylation. BMC Genomics 14685 14:1

Duan F, Chen X, Yuan L, Song Y, Wang A, Lv Q et al (2015) Conservation of imprinting of Neuronatin (Nnat) in rabbits. Springerplus. 4:1

Gu T, Su X, Zhao S, Li C (2014) Methylation differences of the neuronatin gene promoter region in liver between normal and cloned pigs. Anim Genet 45(1):122-124

Hubertus J, Zitzmann F, Trippel F, Muller-Hocker J, Stehr M, von Schweinitz D et al (2013) Selective methylation of CpGs at regulatory binding sites controls NNAT expression in Wilms tumors. PLOS ONE 8(6):e67605 
Kuerbitz SJ, Pahys J, Wilson A, Compitello N, Gray TA (2002) Hypermethylation of the imprinted NNAT locus occurs frequently in pediatric acute leukemia. Carcinogenesis 23(4):559-564

Li X, Hamano K, Qian XQ, Funauchi K, Furudate M, Minato Y (1999) Oocyte activation and parthenogenetic development of bovine oocytes following intracytoplasmic sperm injection. Zygote 7(3):233-237

Schulz R, McCole RB, Woodfine K, Wood AJ, Chahal M, Monk D et al (2009) Transcript- and tissue-specific imprinting of a tumour suppressor gene. Hum Mol Genet 18(1):118-127

Seisenberger S, Peat JR, Reik W (2013) Conceptual links between DNA methylation reprogramming in the early embryo and primordial germ cells. Curr Opinion Biol 25(3):281-288
Sowpati DT, Thiagarajan D, Sharma S, Sultana H, John R, Surani A et al (2008) An intronic DNA sequence within the mouse Neuronatin gene exhibits biochemical characteristics of an ICR and acts as a transcriptional activator in Drosophila. Mech Dev 125(11-12):963-973

Surani MA (1998) Imprinting and the initiation of gene silencing in the germ line. Cell 93(3):309-312

Ushijima T (2005) Detection and interpretation of altered methylation patterns in cancer cells. Nat Rev Cancer 5(3):223-231

Zaitoun I, Khatib H (2006) Assessment of genomic imprinting of SLC38A4, NNAT, NAP1L5, and H19 in cattle. BMC Genet 7(1):1

\section{Submit your manuscript to a SpringerOpen ${ }^{\circ}$ journal and benefit from:}

- Convenient online submission

- Rigorous peer review

- Immediate publication on acceptance

- Open access: articles freely available online

- High visibility within the field

- Retaining the copyright to your article 